\title{
High performance MIIM diode based on cobalt oxide/titanium oxide
}

\author{
S. B. Herner, ${ }^{1}$ A. D. Weerakkody ${ }^{2}$ A. Belkadi, ${ }^{2}$ and G. Moddel $^{2}$ \\ ${ }^{1}$ RedWave Energy, Boulder, Colorado 80309-0425, USA \\ ${ }^{2}$ Department of Electrical, Computer, and Energy Engineering, University of Colorado, Boulder, \\ Colorado 80309-0425, USA
}

(Received 29 December 2016; accepted 15 May 2017; published online 30 May 2017)

\begin{abstract}
Optical rectennas for infrared energy harvesting commonly incorporate metal/double-insulator/ metal diodes. Required diode characteristics include high responsivity and low resistance near zero bias with a sub-micron area, which have not been obtainable simultaneously. Diodes based on a new material set, $\mathrm{Co} / \mathrm{Co}_{3} \mathrm{O}_{4} / \mathrm{TiO}_{2} / \mathrm{Ti}$ and an area of $0.071 \mu \mathrm{m}^{2}$, provide a median maximum responsivity of $4.1 \mathrm{~A} / \mathrm{W}$, a median zero-bias responsivity of $1.2 \mathrm{~A} / \mathrm{W}$, and a median resistance of $14 \mathrm{k} \Omega$. The highest performing diode has a maximum responsivity of $4.4 \mathrm{~A} / \mathrm{W}$, a zero-bias responsivity of $2.2 \mathrm{~A} / \mathrm{W}$, and a resistance of $18 \mathrm{k} \Omega$. Published by AIP Publishing.

[http://dx.doi.org/10.1063/1.4984278]
\end{abstract}

Metal-insulator-metal (MIM) or metal-insulator-insulator-metal (MIIM) diodes are incorporated with micron-scale antennas in optical rectennas for converting infrared radiation into electrical power. They are suited for such an application due to their high frequency rectification properties ${ }^{1}$ and relatively low cost, as compared to diodes formed on single crystal substrates. Their rectification characteristics, as determined from direct current (DC) current-voltage $[I(V)]$ measurements, are usually inferior to those of semiconductor diodes. Figures of merit for these diodes are zerobias responsivity, defined as

$$
\beta_{0}=\left[\frac{d^{2} I}{2 d^{2} V}\right]_{V=0}
$$

and zero bias resistance, defined as

$$
R_{D}=\left[\frac{d V}{d I}\right]_{V=0} .
$$

It is desirable to have a large responsivity at low, or most preferably, zero bias voltage. The self-bias operating voltage for power conversion is estimated to be between 30 and $100 \mathrm{mV}$ for this device. This range is determined by the negligible asymmetry of the diode at less than $30 \mathrm{mV}$ and the energy cost of biasing the diode at more than $100 \mathrm{mV}$. It is desirable to have low resistance $(\mathrm{R})$ and capacitance $(\mathrm{C})$ to minimize the RC time constant of the device and to match the diode impedance to that of the antenna for efficient power transfer. ${ }^{2}$ One way to reduce capacitance is to reduce the area of the diode. Previous reports of MIM or MIIM diodes with large zero bias responsivity $\left(\beta_{0}>1\right)$ have been accompanied by large resistances. ${ }^{3-8} \mathrm{~A}$ large resistance is undesirable for energy harvesting. Diodes with noble metal contacts such as $\mathrm{Au}$ and $\mathrm{Pt}$ are less suitable for integration with other devices, such as silicon-based transistors, in which rapid diffusion of these metals into the silicon devices would be fatal.

Metal-insulator-metal diodes with two insulators (MIIM) having different band gaps and band offsets can result in diodes with greater responsivity and asymmetry compared to diodes with a single insulator (MIM). ${ }^{9}$ We demonstrate an
MIIM diode with high responsivity and low resistance. Reported materials for MIIM diodes have included $\mathrm{Ni} / \mathrm{NiO} /$ $\mathrm{ZnO} / \mathrm{Cr},{ }^{6} \mathrm{Cr} / \mathrm{Al}_{2} \mathrm{O}_{3} / \mathrm{HfO}_{2} / \mathrm{Cr}{ }^{7} \mathrm{ZrCuAlNi} / \mathrm{Al}_{2} \mathrm{O}_{3} / \mathrm{HfO}_{2} / \mathrm{Al},{ }^{10}$ and $\mathrm{ZrCuAlNi} / \mathrm{Al}_{2} \mathrm{O}_{3} / \mathrm{Ta}_{2} \mathrm{O}_{5} / \mathrm{Al}^{11}$ The use of $\mathrm{Co}_{3} \mathrm{O}_{4}$ and $\mathrm{TiO}_{2}$ insulators with relative dielectric constants $\left(\epsilon_{\mathrm{r}}\right)$ of 13 and $15-110$, respectively, and native metal contacts Co and Ti (work functions $=5.0$ and $4.3 \mathrm{eV}$, respectively), enables low diode resistance compared to insulators with low dielectric constants, such as $\mathrm{SiO}_{2}$ and $\mathrm{Al}_{2} \mathrm{O}_{3} \quad\left(\epsilon_{\mathrm{r}}=3.9\right.$ and 9, respectively). ${ }^{12}$ However, the benefit of lower resistance from high dielectric constant materials is partially offset by the higher capacitance of the materials. Finally, the use of refractory metal contacts enables easier integration of these devices with other devices that are sensitive to noble metal contamination. We describe device fabrication and characterization and discuss a mechanism for the measured behavior.

Devices were fabricated on $100 \mathrm{~mm}$ diameter silicon wafers. A $3000 \AA$-thick $\mathrm{SiO}_{2}$ film was deposited on the wafer by plasma-enhanced chemical vapor deposition (PECVD) at a temperature of $300{ }^{\circ} \mathrm{C}$. Photoresist was then applied and patterned, and a $500 \AA$-thick cobalt film was evaporated onto the wafers, preceded by a $50 \AA$-thick titanium film to improve adhesion of the cobalt film. The photoresist was lifted off, forming the bottom Co electrode of the diode. A cobalt oxide film was grown on the patterned Co by plasma oxidation at 30 Watts $(\mathrm{W})$ in an $\mathrm{O}_{2}$ environment at a pressure of 50 mTorr for 30 seconds.

Cobalt oxide can take several different forms, including $\mathrm{CoO}, \mathrm{Co}_{2} \mathrm{O}_{3}$, and $\mathrm{Co}_{3} \mathrm{O}_{4} \cdot{ }^{13} \mathrm{X}$-ray photoelectron spectroscopy (XPS) was performed on the cobalt oxide film to determine the phase. High-resolution spectroscopy on the on Co $1 \mathrm{~s}$, Co 2p, and Co Auger regions using a pass energy of $40 \mathrm{eV}$, and a peak fitting for the Co $2 \mathrm{p}_{3 / 2}$ core level was in agreement with the peak fitting done for $\mathrm{Co}_{3} \mathrm{O}_{4}$ by Biesinger et al. ${ }^{14}$ Furthermore, the Co Auger parameter was calculated as $1553.7 \mathrm{eV}$, which is about the same as the reported $1552.9 \mathrm{eV}$ for $\mathrm{Co}_{3} \mathrm{O}_{4} \cdot{ }^{15}$ From this analysis, we conclude that the cobalt oxide film is $\mathrm{Co}_{3} \mathrm{O}_{4}$.

The $\mathrm{Co}_{3} \mathrm{O}_{4}$ thickness was measured to be $25 \AA$ by variable angle spectroscopic ellipsometry (VASE). The $\mathrm{TiO}_{2}$ 
film was deposited by reactive sputtering at a pressure of 3 mTorr in an environment of $60 \% \mathrm{O}_{2}$ and $40 \% \mathrm{Ar}$, and a power of $60 \mathrm{~W}$, for $180 \mathrm{~s}$. The $\mathrm{TiO}_{2}$ film was estimated to be $27 \AA$ in thickness by depositing a much thicker film, measuring the thickness, extracting a deposition rate, and extrapolating to lesser deposition times. A $50 \AA$-thick titanium film was evaporated onto $\mathrm{TiO}_{2}$, followed by a $2000 \AA$ A-thick sputtered niobium film.

We used industry-standard $248 \mathrm{~nm}$ lithography to fabricate devices, practical for commercial applications, compared to reports of electron beam-based lithography, which is not practical for commercial applications. The $\mathrm{Co}_{3} \mathrm{O}_{4} /$ $\mathrm{TiO}_{2} / \mathrm{Ti} / \mathrm{Nb}$ stack was then patterned and etched in a reactive ion etching (RIE) tool using boron trichloride $\left(\mathrm{BCl}_{3}\right)$ and chlorine $(\mathrm{Cl})$ at a pressure of $20 \mathrm{mT}$ Torr and a power of $90 \mathrm{~W}$. After photoresist removal, a pillar of $\mathrm{Co}_{3} \mathrm{O}_{4} / \mathrm{TiO}_{2} / \mathrm{Ti} / \mathrm{Nb}$ with $\mathrm{Nb}$ on top was left on the Ti/Co interconnect. Next, a passivating layer of $\mathrm{SiO}_{2}$ was deposited by PECVD at a temperature of $200{ }^{\circ} \mathrm{C}$. $\mathrm{SiO}_{2}$ was then partially removed by chemomechanical polishing (CMP), exposing $\mathrm{Nb}$. $\mathrm{Nb}$ acted as a polish stop, as its CMP removal rate is far less than the removal rate of $\mathrm{SiO}_{2}$. The remaining $\mathrm{SiO}_{2}$ was then patterned and etched in a selected area in an RIE tool using $\mathrm{CF}_{4}$ at a pressure of 20 mTorr and a power of $50 \mathrm{~W}$. After $\mathrm{SiO}_{2}$ etching and photoresist removal, $50 \AA$-thick titanium and $2000 \AA$ A-thick aluminum films were deposited by sputtering. This Ti/Al bilayer was patterned and etched in an RIE tool at a pressure of $20 \mathrm{mT}$ Torr and a power of $90 \mathrm{~W}$ with $\mathrm{BCl}_{3}$ and $\mathrm{Cl}$, resulting in separate contacts to the cobalt film and the niobium film, the lower and upper contacts of the MIIM diode, respectively, as shown schematically in Fig. 1. Three diode sizes were fabricated on each wafer: $0.3,0.5$, and $1.0 \mu \mathrm{m}$ diameters, corresponding to diode areas of 0.071 , 0.20 , and $0.79 \mu \mathrm{m}^{2}$.

A sample diode was characterized by cross sectional transmission electron microscopy (TEM), and the diode oxide films were found to be rough. The roughness precluded a clear measurement of the film thickness from the TEM foil. Smoother oxide films and interfaces have been associated with larger diode asymmetries and may provide larger asymmetries and responsivities in these diodes. ${ }^{16}$

An $I(V)$ plot for a typical device with an area of 0.071 $\mu \mathrm{m}^{2}$ is shown in Fig. 2. The measurement sweep was done from -0.3 to $+0.3 \mathrm{~V}$, as the devices operate near zero bias in an energy harvesting application. The diodes are weakly rectifying at these low voltages, with typical current

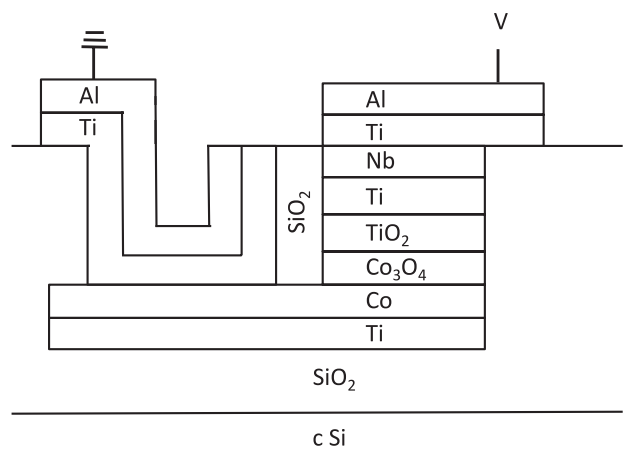

FIG. 1. Cross sectional schematic of the diode.

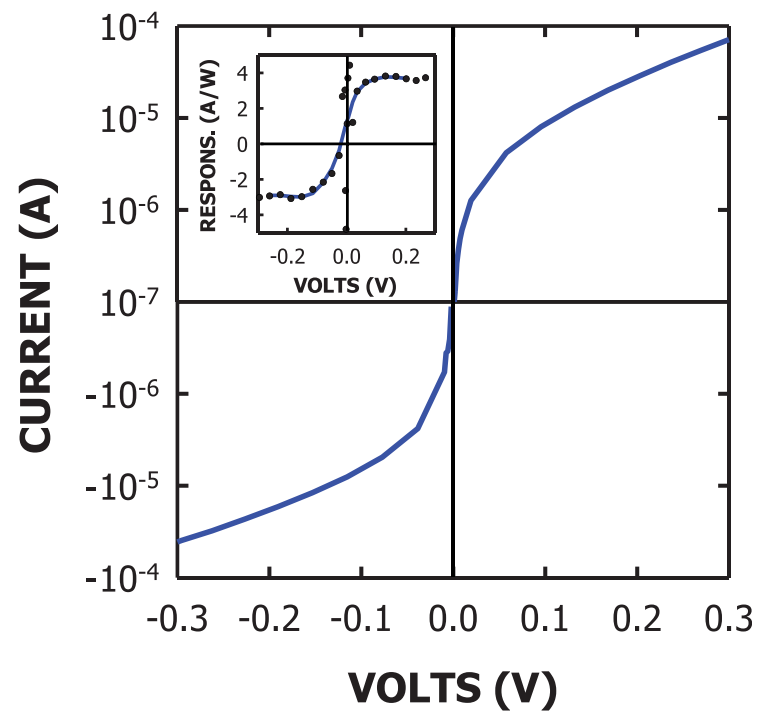

FIG. 2. Current-voltage plot of a typical $\mathrm{Co} / \mathrm{Co}_{3} \mathrm{O}_{4} / \mathrm{TiO}_{2} / \mathrm{Ti}$ diode. The inset shows the responsivity-voltage plot of the same diode. The actual responsivity data are shown as dots, and the blue line represents a seventh order polynomial fit to the actual data.

asymmetries of 1.06 at $30 \mathrm{mV}$ and 1.20 at $100 \mathrm{mV}$. The fitted responsivity of this diode is shown in the inset of Fig. 2. The data have been fitted by a seventh order polynomial to reduce the effects of measurement noise. Fitting the data to a polynomial is necessitated by the large noise values caused by the second derivative of raw data. ${ }^{17}$ The zero bias responsivity of this particular diode is $1.3 \mathrm{~A} / \mathrm{W}$, with a maximum responsivity of $4.1 \mathrm{~A} / \mathrm{W}$ at $130 \mathrm{mV}$ and a zero-bias resistance of $16 \mathrm{k} \Omega$.

Probability plots of zero bias and maximum responsivities, and zero-bias resistances of 22 devices on the wafer, are shown in Figs. 3 and 4. The probability plots allow the visualization of all of the values of the diodes measured in a single figure. The distributions of diode responsivity and resistance can be attributed to variations in the thickness of the oxide films and in diode size arising in variability of the etch rate across the wafer, among other possibilities. The increasing zero bias responsivity with the decreasing diode

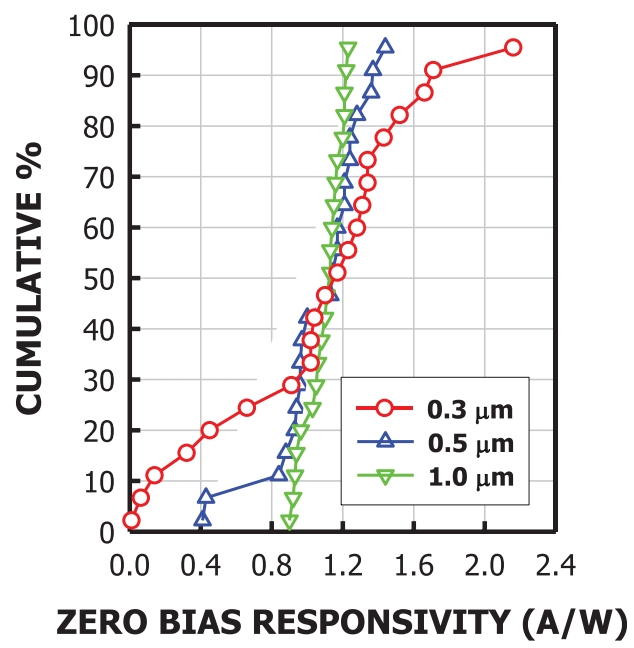

FIG. 3. Probability plot of the zero bias resistance for 22 devices of each size after annealing at $222^{\circ} \mathrm{C}$ for $10 \mathrm{~min}$ in air. 


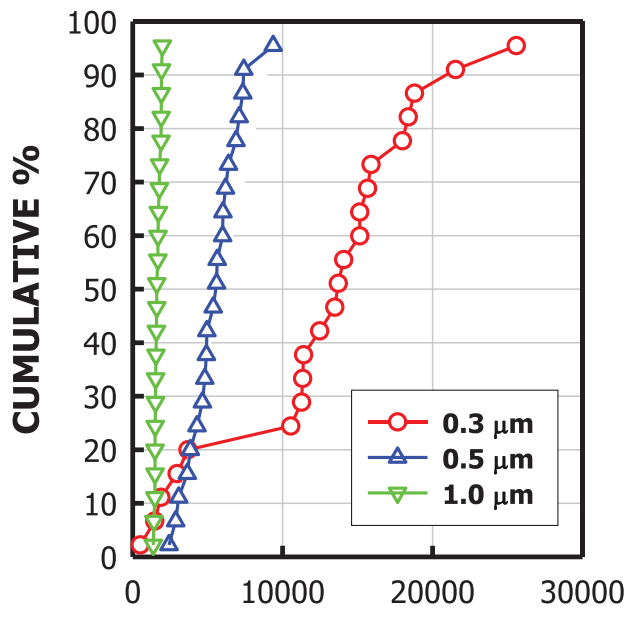

ZERO BIAS RESISTANCE $(\Omega)$

FIG. 4. Probability plot of zero bias responsivity for 22 devices of each size after annealing at $222^{\circ} \mathrm{C}$ for $10 \mathrm{~min}$ in air.

area (Fig. 3) is attributed to an areal defect density. With the decreasing diode size, the probability of having a defect decreases and can lead to a higher responsivity. ${ }^{2}$ However, the probability of a defect even in very small diodes remains. In fact, given the roughness of the films, the distributions of zero-bias responsivity and resistance shown in Figs. 3 and 4 are surprisingly small: the smallest diodes have relative one sigma values of $54 \%$ for both the zero-bias responsivity and resistance, even when including diodes on the wafer that clearly did not exhibit high yield. We believe that it is critical to report distributions of a plurality of device measurements, instead of single device results.

Table I compares the values of responsivity, resistance, and diode size in this report with other high responsivity MIM or MIIM diodes from other reports. Only publications in which the diode size, maximum responsivity, zero bias responsivity, and zero bias resistance values are reported are considered. Sensitivity values reported are converted into responsivity values by dividing by 2 . Note that for the reports of diodes with comparable zero bias responsivity, the resistance and diode size are considerably larger, and so, the last column normalizes the resistances in other reports based on the diode size used in this study. Without being scaled to smaller areas, the capacitance values of the larger diodes would be unacceptably large for energy harvesting applications.

Minimizing both the resistance and capacitance of these diodes is crucial for their application in energy harvesting.
The RC time constant must be smaller than the reciprocal of the operating frequency to couple energy efficiently from the antenna. ${ }^{18}$ A large capacitance will short out the AC excitation across the antenna. As the diode oxide films must be thin to facilitate sufficient electron tunneling, the only means to drastically reduce the capacitance is to reduce the size of the diode area. The use of mid-range dielectric constant metal oxides $\mathrm{Co}_{3} \mathrm{O}_{4}$ and $\mathrm{TiO}_{2}$ results in a smaller resistance than the use of low dielectric constant oxides such as $\mathrm{SiO}_{2}$ and $\mathrm{Al}_{2} \mathrm{O}_{3}$. Although we are unable to measure the capacitance of these diodes, the capacitance can be estimated from the thickness and area of the films and the published dielectric constants of the films. The estimated RC time constant of these diodes is sufficiently small for operation at low terahertz frequencies.

In thin MIIM diodes, the conduction of charge carriers occurs via quantum tunneling through the insulators. The fast electron tunneling process through the insulator thickness of several nanometers happens in femtoseconds. The tunnel current is calculated from the electron transmission probability and the Fermi distribution of electrons in the metal and leads to nonlinear current-voltage $\mathrm{I}(\mathrm{V})$ characteristics that depend on the shape of the barrier. ${ }^{19}$ The experimental $\mathrm{I}(\mathrm{V})$ characteristics of a fabricated $\mathrm{Co} / \mathrm{Co}_{3} \mathrm{O}_{4} / \mathrm{TiO}_{2} / \mathrm{Ti}$ diode are compared to simulation results generated using a transfer-matrix method diode simulator, shown in Fig. 5. ${ }^{9}$ Material parameters used in the simulation are work functions of $4.8 \mathrm{eV}$ and $4.5 \mathrm{eV}$ for $\mathrm{Co}$ and $\mathrm{Ti}$, respectively, and electron affinities of $4.55 \mathrm{eV}$ and $4.17 \mathrm{eV}$ for $\mathrm{Co}_{3} \mathrm{O}_{4}$ and $\mathrm{TiO}_{2}$, respectively. The inset illustrates the energy band diagram of this diode under zero bias. The triangular potential well formed between the two insulators indicates a resonant MIIM diode, with Fowler-Nordheim tunneling through $\mathrm{Co}_{3} \mathrm{O}_{4}$ and direct tunneling through $\mathrm{TiO}_{2}$ for a small bias of either polarity. ${ }^{11}$ For positive bias polarities, where electrons tunnel from Co to $\mathrm{Ti}$, a resonant state is formed in the potential well, resulting in enhanced $\mathrm{I}(\mathrm{V})$ nonlinearity. For negative bias, electrons tunnel through $\mathrm{TiO}_{2}$ with a lower transmission probability than for positive bias since the resonant well is no longer formed. The simulated I(V) curves are in good agreement with the measured characteristics, indicating that the pure tunneling analysis provides accurate simulations for thin metal-insulator(s)-metal diodes. As the simulation assumes perfect insulators, differences from the experimental diode can be attributed to charging of the well, defects, surface states, and interface charge.

The maximum temperature during fabrication after MIIM film deposition was $200^{\circ} \mathrm{C}$, which occurred during

TABLE I. Comparison of measured MIM and MIIM diode characteristics.

\begin{tabular}{|c|c|c|c|c|c|c|}
\hline References & MIM or MIIM & Size $\left(\mu \mathrm{m}^{2}\right)$ & $\begin{array}{l}\text { Maximum } \\
\text { responsivity A/W }\end{array}$ & $\begin{array}{l}\text { Zero bias } \\
\text { responsivity A/W }\end{array}$ & Zero bias resistance & $\begin{array}{l}\text { Zero bias resistance } \\
\text { normalized to } 0.071 \mu \mathrm{m}^{2}\end{array}$ \\
\hline Krishnan et al. ${ }^{3}$ & $\mathrm{Ni} / \mathrm{NiO} / \mathrm{Cr} / \mathrm{Au}$ & 1 & 2.5 & 0.5 & $500 \mathrm{k} \Omega$ & $7.04 \mathrm{M} \Omega$ \\
\hline Dagenais et al. ${ }^{4}$ & $\mathrm{Si} / \mathrm{SiO}_{2} / \mathrm{Au}$ & 0.35 & -7.3 & 2.5 & $120 \mathrm{M} \Omega$ & $592 \mathrm{M} \Omega$ \\
\hline Bean et al. ${ }^{5}$ & $\mathrm{Al} / \mathrm{Al}_{2} \mathrm{O}_{3} / \mathrm{Pt}$ & 0.56 & -1.3 & 0.3 & $220 \mathrm{k} \Omega$ & $1.73 \mathrm{M} \Omega$ \\
\hline Singh et al. ${ }^{6}$ & $\mathrm{Ni} / \mathrm{NiO} / \mathrm{ZnO} / \mathrm{Cr}$ & 400 & 8.0 & 1.3 & $234 \mathrm{M} \Omega$ & $1.32 \mathrm{G} \Omega$ \\
\hline $\begin{array}{l}\text { Median values in this work, } \\
\text { after } 222^{\circ} \mathrm{C} \text { anneal }\end{array}$ & $\mathrm{Co} / \mathrm{Co}_{3} \mathrm{O}_{4} / \mathrm{TiO}_{2} / \mathrm{Ti}$ & 0.071 & 4.4 & 1.2 & $14 \mathrm{k} \Omega$ & $14 \mathrm{k} \Omega$ \\
\hline
\end{tabular}




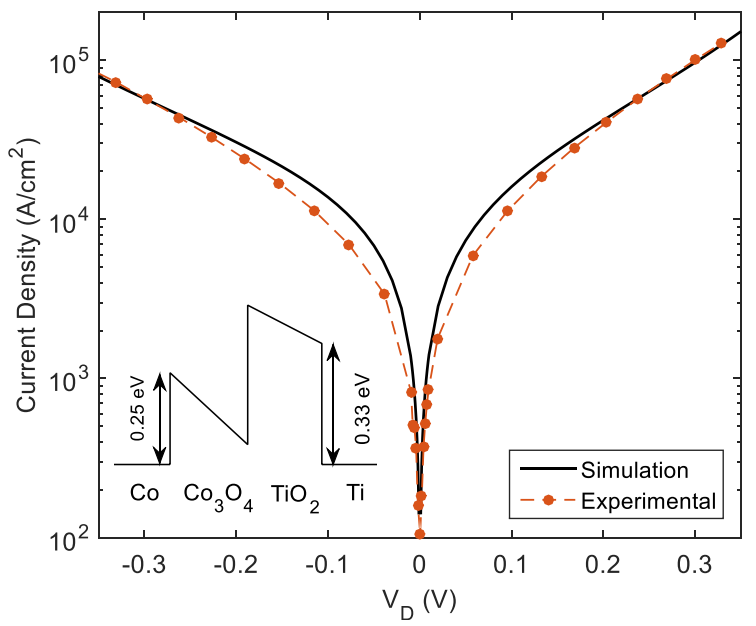

FIG. 5. Comparison of simulated and experimental $I(V)$ characteristics for a $\mathrm{Co} / \mathrm{Co}_{3} \mathrm{O}_{4} / \mathrm{TiO}_{2} / \mathrm{Ti}$ diode. Thicknesses of $1.1 \mathrm{~nm}$ and $1.05 \mathrm{~nm}$ were used for $\mathrm{Co}_{3} \mathrm{O}_{4}$ and $\mathrm{TiO}_{2}$, respectively, in the simulation. The inset illustrates the energy-band profiles of this diode at $0 \mathrm{~V}$.

PECVD $\mathrm{SiO}_{2}$ deposition. After fabrication, the diodes were annealed on a hot plate in an atmosphere for $10 \mathrm{~min}$ and were measured again after each anneal. The median and standard deviations of the zero bias responsivities and the resistances for $0.071 \mu \mathrm{m}^{2}$ area diodes after annealing of the same are shown in Fig. 6. The median value of the zero bias resistance peaks after the first anneal at $222^{\circ} \mathrm{C}$ at $1.2 \mathrm{~A} / \mathrm{W}$ with a median resistance $14 \mathrm{k} \Omega$. The highest performing diode was measured after $222^{\circ} \mathrm{C}$ anneal and has a maximum responsivity of $4.4 \mathrm{~A} / \mathrm{W}$, a zero-bias responsivity of $2.2 \mathrm{~A} / \mathrm{W}$, and a resistance of $18 \mathrm{k} \Omega$. After annealing at $256^{\circ} \mathrm{C}$, the median zero bias responsivity is $0.9 \mathrm{~A} / \mathrm{W}$ and the median resistance is $2 \mathrm{k} \Omega$. This last value is by far one of the lowest resistance values measured for a device with substantial responsivity and a small diode area. The decrease in the resistance with anneal is puzzling. We speculate that the metal/ oxide interface may continue to roughen when annealed, causing an increase in local electric fields, leading to a decrease in the effective thickness of the oxide(s) and resultant decrease in the resistance of the diode. In any case, such a low value of the resistance is desirable for use in optical rectennas.

In conclusion, we describe an MIIM diode composed of $\mathrm{Co} / \mathrm{Co}_{3} \mathrm{O}_{4} / \mathrm{TiO}_{2} / \mathrm{Ti}$ with an area of $0.071 \mu \mathrm{m}^{2}$ with a median maximum responsivity of $4.1 \mathrm{~A} / \mathrm{W}$, a median zero-bias responsivity of $1.2 \mathrm{~A} / \mathrm{W}$, and a median resistance of $14 \mathrm{k} \Omega$. The highest performing diode has a maximum responsivity of $4.4 \mathrm{~A} / \mathrm{W}$, a zero-bias responsivity of $2.2 \mathrm{~A} / \mathrm{W}$, and a resistance of $18 \mathrm{k} \Omega$. The diode has a smaller area and a lower resistance than diodes reported previously, and these properties make it suitable for use in optical rectennas for energy harvesting. A transfer matrix diode simulation of I(V) characteristics indicates a pure tunneling mechanism for the diode. The diodes show a drastic reduction in the resistance after an anneal of up to $256^{\circ} \mathrm{C}$, with only a modest reduction in zero bias responsivity.

The authors of this paper express their appreciation to the staff of the University of California at Santa Barbara (UCSB)

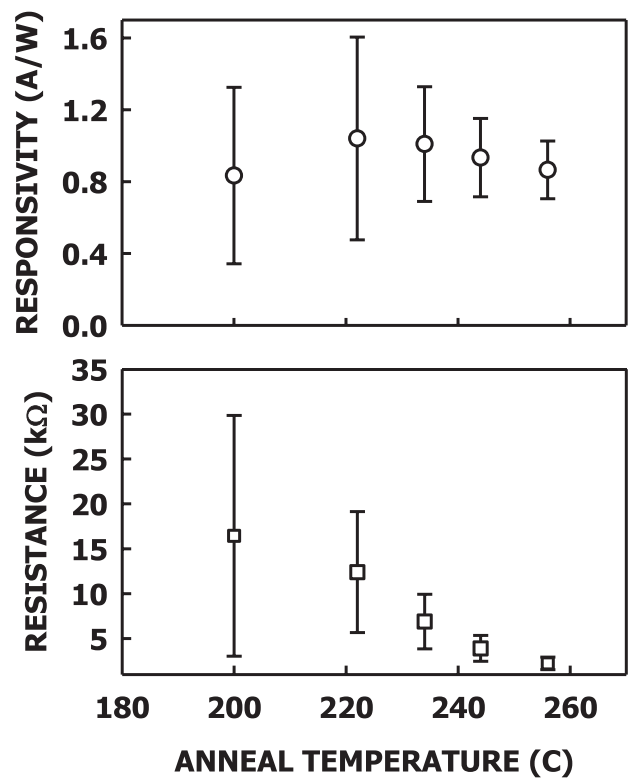

FIG. 6. Median and standard deviation of zero bias responsivity (upper plot) and zero bias resistance (lower plot) for 22 devices with an area of $0.071 \mu \mathrm{m}^{2}$, after annealing for $10 \mathrm{~min}$ in air at the temperature indicated.

Nanotech facility, where these devices were fabricated, and to David Doroski for help with fabrication and Brad Pelz for help with measurements and fitting of the same. The work at the University of Colorado was supported by a grant from RedWave Energy. G. Moddel holds stock in RedWave Energy.

${ }^{1}$ E. Donchev, J. S. Pang, P. M. Gammon, A. Centeno, F. Xie, P. K. Petrov, J. D. Breeze, M. P. Ryan, D. J. Riley, and N. M. Alford, MRS Energy Sustainability: A Rev. J. 1, 1-34 (2014).

${ }^{2}$ S. Grover and G. Moddel, IEEE J. Photovoltaics 1, 78-83 (2011).

${ }^{3}$ S. Krishnan, H. La Rosa, E. Stefanakos, S. Bhansali, and K. Buckle, Sens. Actuators, A 142, 40-47 (2008).

${ }^{4}$ M. Dagenais, K. Choi, F. Yesilkoy, A. N. Chryssis, and M. C. Peckerar, Proc. SPIE 7605, 1-12 (2010).

${ }^{5}$ J. Bean, B. Tiwari, G. Szakmány, G. H. Bernstein, P. Fay, and W. Porod, in 2008 IEEE Silicon Nanoelectronics Workshop (2008), pp. 1-2.

${ }^{6}$ A. Singh, R. Ratnadurai, R. Kumar, S. Krishnan, Y. Emirov, and S. Bhansali, Appl. Surf. Sci. 334, 197 (2015).

${ }^{7}$ P. Maraghechi, A. Forough-Abari, K. Cadien, and A. Y. Elezzabi, Appl. Phys. Lett. 99, 253503 (2011).

${ }^{8}$ A. D. Weerakkody, N. Sedghi, I. Z. Mitrovic, H. van Zalinge, I. Nemr Noureddine, S. Hall, J. S. Wrench, P. R. Chalker, L. J. Phillips, R. Trehane, and K. Durose, Microelectron. Eng. 147, 298 (2015).

${ }^{9}$ S. Grover and G. Moddel, Solid State Electron. 67, 94 (2012).

${ }^{10}$ N. Alimardani and J. F. Conley, Jr., Appl. Phys. Lett. 102, 143501 (2013).

${ }^{11}$ N. Alimardani and J. F. Conley, Jr., Appl. Phys. Lett. 105, 082902 (2014).

${ }^{12}$ R. V. Rao and A. Smakula, J. Appl. Phys. 36, 2031 (1965).

${ }^{13}$ K. Deori and S. Deka, CrystEngComm 15, 8425 (2013).

${ }^{14}$ M. C. Biesinger, B. P. Payne, A. P. Grosvenor, L. W. M. Lau, A. R. Gerson, R. St, and C. Smart, Appl. Surf. Sci. 257, 2717 (2011).

${ }^{15} \mathrm{~J}$. Haber and L. Ungier, J. Electron Spectrosc. Relat. Phenom. 12, 305 (1977).

${ }^{16}$ N. Alimardani, E. W. Cowell III, J. F. Wagner, J. F. Conley, Jr., D. R. Evans, M. Chin, S. J. Kilpatrick, and M. Dubey, J. Vac. Sci. Technol., A 30, 01A113 (2012).

${ }^{17}$ B. Pelz, A. Belkadi, S. B. Herner, and G. Moddel, "Avoiding erroneous analysis of MIM diode current-voltage characteristics: exponential fitting" (unpublished).

${ }^{18}$ S. Joshi, Ph.D. thesis, University of Colorado, Boulder, 2015, p. 89.

${ }^{19}$ J. G. Simmons, J. Appl. Phys. 35, 2472 (1964). 